\title{
Friction Measurements with Molten Chocolate
}

\author{
M. Masen ${ }^{1}$-P. M. E. Cann ${ }^{1}$ (1)
}

Received: 1 March 2017 / Accepted: 16 November 2017 / Published online: 26 December 2017

(c) The Author(s) 2018. This article is an open access publication

\begin{abstract}
A novel test is reported which allows the measurement of the friction of molten chocolate in a model tongue-palate rubbing contact. Friction was measured over a rubbing period of $150 \mathrm{~s}$ for a range of commercial samples with different cocoa content $(85-5 \% \mathrm{w} / \mathrm{w})$. Most of the friction curves had a characteristic pattern: initially a rapid increase occurs as the highviscosity chocolate melt is sheared in the contact region followed by friction drop as the film breaks down. The exceptions were the very high $(85 \%)$ and very low $(\sim 5 \%)$ cocoa content samples which gave fairly constant friction traces over the test time. Differences were observed in the initial maximum and final friction coefficients depending on chocolate composition. Generally, the initial maximum friction increased with increasing cocoa content. At the end of the test, the rubbed films on the lower slide were examined by optical microscopy and infrared micro-reflection spectroscopy. In the rubbed track, the chocolate structure was severely degraded and predominately composed of lipid droplets, which was confirmed by the IR spectra. The new test provides a method to distinguish between the friction behaviour of different chocolate formulations in a rubbing low-pressure contact. It also allows us to identify changes in the degraded chocolate film that can be linked to the friction profile. Further development of the test method is required to improve simulation of the tongue-palate contact including the effect of saliva and this will be the next stage of the research.
\end{abstract}

Keywords Oral processing $\cdot$ Friction $\cdot$ Food technology, lipids

\section{Introduction}

The perception of creaminess and smoothness is primarily related to friction experienced in the tongue-palate contact during mastication [1]. One popular snack where creaminess and smoothness are prized qualities is chocolate and the development of low fat/sugar analogues must satisfy consumer expectations in this regard. One of the problems in formulating such products is quantifying the sensory properties of creaminess/smoothness in the laboratory in a way which relates to consumer experience. The aim of this paper was to develop a simple laboratory test which measures the friction properties of chocolate in a model oral contact (tongue/palate) and discriminates between different products. It is hoped to define a test which will facilitate the

The original version of this article was revised due to a retrospective Open Access order.

P. M. E. Cann

p.cann@imperial.ac.uk

1 Tribology Group, Department of Mechanical Engineering, Imperial College, London, UK development of new products and also provide insights into fundamental mechanisms of oral processing.

Chocolate is a solid mixture of particulates (cocoa solids, sugar crystals, milk solids) dispersed in a continuous phase (mainly cocoa butter) [2]. Additional components include emulsifiers (usually soya lecithin) and vegetable oils (e.g. shea, palm). The cocoa (fat and solids), sugar and milk content are varied to give a range of products (e.g. dark, milk, white). The composition and definition of different chocolate types and taste preferences vary across the globe and are the subject of intense on-line debate. In the EU, the different types of chocolate and their allowed composition are defined in EU directive 2000/36/EC [3]. These are summarised in Table 1.

Chocolate is prepared by a combined mixing (shearing) and heating process usually referred to as "conching" followed by tempering to give the final product [2]. The resulting bulk flow properties of chocolate have been extensively studied by rheology [4-6]; molten chocolate is classified as a non-Newtonian fluid that exhibits yield points and plastic viscosity [4-6]. Although rheology is important in determining flow properties for manufacturing processes, it is not 
Table 1 EU Composition of common chocolate types [2]

\begin{tabular}{llll}
\hline Composition wt $\%$ & Dark $(\%)$ & Milk $^{\mathrm{b}}(\%)$ & White $(\%)$ \\
\hline Total cocoa solids & $\geq 35$ & $\geq 25$ & \\
Cocoa butter & $\geq 18$ & & $\geq 20$ \\
Non-fat cocoa solids & $\geq 14$ & $\geq 2.5$ & \\
Milk fat & & $\geq 3.5$ & \\
Total fat & & $\geq 25$ & $\geq 14$ \\
Milk solids & & $\geq 14$ & \\
\hline
\end{tabular}

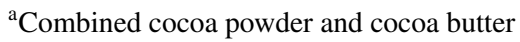

b"Family milk chocolate" in the UK, Ireland and Malta may contain $20 \%$ cocoa solids

necessarily useful in predicting or explaining the different texture attributes experienced during eating [1]. It is widely considered that as the film in the tongue-palate interface is sheared and thins, it is the tribological rather than rheology mechanism which dominates [1, 7-9].

Chocolate as a tribological material and the effect of oral processing on friction have proved difficult to study, and very few papers have been published [7-9]. Typically, molten chocolate is introduced into a sliding contact and friction coefficient measured over a range or speed or load values. The contacting specimens vary: polymer (PDMS)/ polymer (PDMS) [8] or polymer/ceramic [7, 9] have been used. In these papers [7-9], the effects of chocolate composition and preparation method on friction were studied. Although differences in the friction values and response to changing speed for different chocolate composition were observed, it was unclear how to relate these trends to mouthfeel texture attributes.

Eating chocolate is widely perceived (or marketed!) as a self-indulgent experience which is influenced by flavour and viscosity but dominated by the oral perception of creaminess and smoothness [10]. Thus consumer expectation is high particularly for the more expensive brands. In the consumption of chocolate, there are a number of distinct processes: initial biting and snap (tooth-chocolate), grinding and mixing with saliva (tooth-tooth) and final processing (tongue-palate) before swallow [10]. Hoskin [2] lists a number of sensory properties associated with the evaluation of chocolate, and these include: colour, surface appearance, break, texture, aroma and taste (sweetness/bitterness). The development of new recipes, for example with reduced fat or sugar, must meet the consumer anticipation of mouthfeel and satiation however the product is eaten. In the current work, the focus is on the tongue-palate process rather than the initial snap.

The composition of the continuous lipid phase plays an important role in texture perception [10] as the product must be solid at room temperature and then melt rapidly once introduced into the mouth. Cocoa butter [11] is composed of triglycerides which contain three fatty acid "tails" attached to a glycerol backbone. The most common fatty acids (over 95\%) are oleic acid (35\% unsaturated C18), stearic acid (34\% saturated $\mathrm{C} 18)$, and palmitic acid (26\% saturated $\mathrm{C} 16)$. The most abundant glyceride structure $(\sim 89 \%)$ has a symmetrical saturated structure with oleic acid attached in the middle of the glycerol backbone (SOS glyceride) [11]. In some EU countries (UK, Ireland, Malta), the addition of vegetable fat (up to 5\%) is allowed for designated "family" milk chocolate [3], and this is usually in the form of shea or palm oil. Shea butter contains a range of triglyceride fatty acids including oleic acid (40-60\%), stearic acid (20-50\%), linoleic acid (3-11\%), palmitic acid (2-9\%), linolenic acid $(<1 \%)$ and arachidic acid $(<1 \%)$.

Other ingredients will also contribute to the perception of creaminess or smoothness, for example milk chocolate contains milk fats and proteins. Milk fats are predominately triglycerides; again the most abundant forms are oleic (25 wt $\%$ ), stearic (12 wt\%) and palmitic acid (23 wt\%) [11]. Surfactants (e.g. lecithin, polysaccharides, gums) and casein (in milk protein) are added to aid mixing of sugar particles held in the lipid phase. Lecithin, a mixture of phosphoglycerides, is often added (up to $1 \% \mathrm{w} / \mathrm{w}$ ) as it allows reduction of fat content whilst maintaining desirable flow properties (yield value and plastic viscosity) [11].

Although there is a considerable body of published literature on chocolate formulation, rheology and structure, there are relatively few tribological studies [7-9]. There are laboratory tests to measure "snap" [11] but not "creaminess" or "smoothness". At present, the industry still relies on panel testing to assess these attributes [11]. The development of new healthier recipes with lower fat content is one aim of the industry and to be accepted must obviously meet the consumer mouthfeel expectations. The development of a simple screening test to measure friction under model mouthfeel conditions which is able to discriminate between different chocolate types would contribute to this process. Obviously, an important step in the development and validation of a screening test would be to compare friction measurements to consumer preferences. Texture perception during mastication in the tongue-palate contact is a mixture of initial melting and subsequent creaminess and smoothness attributes. The aim of this study therefore was to develop a simple tribology test which would capture the essential features of chocolate mastication in the tongue-palate contact after melting. The next stage, which is the validation of the approach by comparison with panel testing, awaits industry participation.

A modified HFRR device (High-Frequency Reciprocating Rig, PCS Instruments, UK) was used to measure friction in a chocolate-palate (model) contact. An earlier paper describes the application of the HFRR device to food studies [12]; in this case an upper poly-dimethyl silicone ball (PDMS, 
tongue model) was loaded and rubbed against a lower stationary glass specimen (palate model). Friction was measured over a rubbing time of $240 \mathrm{~s}$ for a reciprocating contact (10 Hz, $1 \mathrm{~mm}$ stroke). The test conditions were chosen to represent the movement of the tongue against the palate, where the sliding distance is less than the tongue-palate contact area. During reciprocation, the loaded surfaces do not move significantly outside the contact area, which is analogous to fretting in engineering tribology. Under these conditions, there is minimal entrainment of fresh fluid to the contact zone due to the moving surfaces. In traditional sliding systems where the stroke length is much greater than the contact diameter, fluid is entrained by the moving surfaces, and there is a continual supply of fresh fluid to the rubbing contact. Fluid in the inlet zone experiences very high shear rates $\left(>10^{6} \mathrm{~s}^{-1}\right)$ which may result in shear thinning or in the case of multiphase lubricants (grease, emulsions) phase separation [12]. Thus, in traditional lubrication tests with complex multiphase foods (emulsions, solid dispersions, etc.), the properties (rheology and composition) of the fluid entering the contact will be very different to the bulk material. Thus friction is measured for the inlet-modulated material (possibly phase-separated) rather than the bulk. It is this condition which is used in many previous studies of food tribology where Stribeck-type curves (friction change over a speed range) have been run to characterise the friction properties of food [13]. In contrast, when eating semi-solid food is placed in the oral cavity and then progressively broken down by mastication under load in the rubbing tongue/ palate contact. Very importantly, at the beginning of this process, all components are present and periodically food is replenished in the tongue-palate through an unloading motion rather than by continued flow entrained by the moving surfaces. In the tongue-palate, we consider that the friction is determined by food mechanical/chemical degradation and loss mechanisms from the contact zone rather than entrained flow.

In the earlier paper [12], we outlined the development of a test to measure friction in a model tongue/palate contact for yoghurt. One important aspect was the ability to measure friction change with time as the food is broken down in the rubbing contact thus mimicking the eating experience. The test was used successfully to distinguish between dairy products with different fat contents and to study the effect of surface wetting (hydrophobic/hydrophilic) on friction changes during rubbing [12]. The design of the current test is slightly different as the chocolate is pre-melted onto the glass slide. The upper, reciprocating specimen is a flat polymer disc. Flat-flat specimen configurations are usually avoided in tribology testing due to the problems of the misalignment; however, in this case the softer PDMS surface deformed under load to give an even contact.
In the current paper, the test is applied to commercially available chocolate. A range of cocoa solids and chocolate types ("family" and "luxury") were chosen as commercial examples. Friction change was followed from the initiation of rubbing in a model tongue-palate contact. At the end of the test, the material remaining in the rubbed contact was examined by optical microscopy and infrared spectroscopy. This approach allows us to identify component loss or change and thus contribute to the final friction experienced.

\section{Experimental Programme}

\subsection{Friction Test}

The new HFRR test method uses flat PDMS (polydimethylsiloxane, tongue model) disc ( $5 \mathrm{~mm}$ thick, $6 \mathrm{~mm}$ diameter) loaded and rubbing against a stationary lower glass surface (palate model). This combination of soft/harder surfaces had been used in a number of papers to mimic the tongue/palate contact $[13,14]$. A schematic diagram is shown in Fig. 1a. The lower specimen is a glass microscope slide clamped on the temperature-controlled heating block. A thermocouple in the heating block monitored the temperature. The PDMS

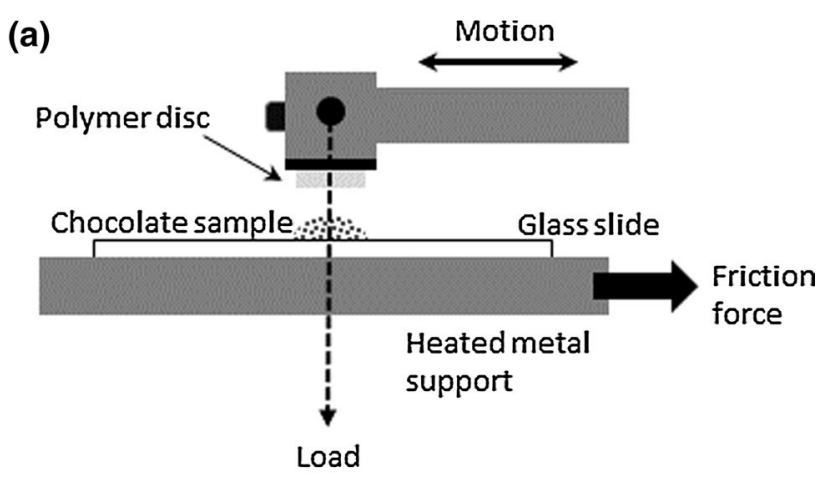

(b)

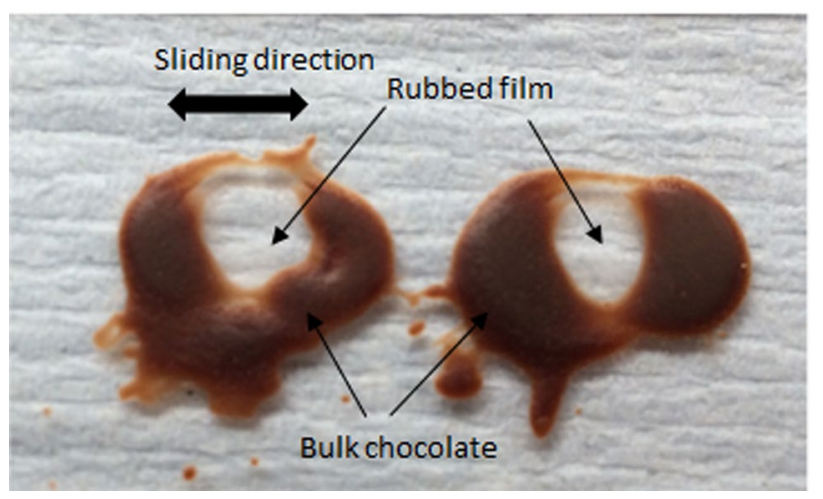

Fig. 1 Schematic diagram of HFRR test configuration and picture of chocolate sample. a HFRR test configuration, b Photograph of two chocolate samples on a glass microscope slide after testing (the background is textured paper underneath the glass slide) 
sample was glued to the upper HFRR specimen holder which is mounted on a shaft driven in a reciprocating motion. The lower glass specimen was preheated to $35^{\circ} \mathrm{C}$ which was held constant for $10 \mathrm{~min}$ before the test started. A small amount $(<0.1 \mathrm{~g})$ of shaved chocolate taken from the middle of the bar and a few flakes were placed on the glass slide and allowed to melt for $30 \mathrm{~s}$ just prior to testing. The chocolate was not pre-sheared before testing.

The reciprocating motion was then started and the PDMS specimen loaded against the glass $(10 \mathrm{~s}$ after the start of reciprocation). Friction (over $150 \mathrm{~s}$ total test time) was recorded from the application of the load. The test conditions are summarised in Table 2. A stroke length of $1.5 \mathrm{~mm}$ was used which gives a sliding speed of $30 \mathrm{~mm} \mathrm{~s}^{-1}$ over most of the cycle within a typical range for tongue speeds quoted by Hiiemae and Palmer [15].

A new glass slide (cleaned with isopropanol) was used for each test. The upper specimen was punched from a PDMS sheet (5 $\mathrm{mm}$ thick) using a 6-mm-diameter biopsy tissue punch. After each test, this was wiped and then cleaned with isopropanol, periodically the disc was replaced. After test, the PDMS surface was examined, but

Table 2 HFRR test conditions

\begin{tabular}{ll}
\hline Parameter & Value \\
\hline $\begin{array}{ll}\text { Test condition } \\
\text { Load }\end{array}$ & $1 \mathrm{~N}$ \\
Temperature & $35{ }^{\circ} \mathrm{C}$ \\
Time & Up to $150 \mathrm{~s}$ \\
Kinematics & Reciprocating sliding: $1.5-\mathrm{mm}$ stroke $10 \mathrm{~Hz}$ \\
Sliding speed & Mid stroke $30 \mathrm{~mm} \mathrm{~s}^{-1}$ \\
Test specimens & \\
Upper & PDMS disc (Duro 30) 5 mm thick, $6 \mathrm{~mm}$ diameter \\
Lower & Glass microscope slide Young's modulus $70 \mathrm{GPa}$ \\
\hline
\end{tabular}

there was no indication of damage due to rubbing. A load of $1 \mathrm{~N}$ was used giving an approximate contact pressure of $30 \mathrm{kPa}$ which is comparable to reported pressures in the tongue/palate contact [16].

The design of the test was kept as simple as possible to establish the basic premise of friction change with rubbing time. The effect of a saliva layer on friction and chocolate film degradation was not investigated but will be considered in the future.

\subsection{Chocolate Specimens}

Commercial chocolate samples were chosen to represent popular types (dark, milk and white) from "family" (designated "A") and "luxury" (designated "B") ranges. These samples were obtained from supermarkets and were representative of UK and US manufacturers. Dark_A, Milk_A and White_A were made by the same manufacturer and are typical of UK family chocolate (Cadbury). The EU chocolate directive [3] allows up to $5 \%$ of vegetable fat (shea, palm oil) to be included. A further sample designated "Candy_EU" was tested which was manufactured by a Belgian company (Koetjesreep). Although this had the appearance of milk chocolate, it was not classified as such and was composed primarily of sugar and vegetable fat with a small amount of cocoa content (5\%). The chocolate samples designated as "luxury" (B) were all made by the same manufacturer (Green and Blacks) and represented the higher price range of chocolate bars. The composition of all the samples is summarised in Table 3; this information was gleaned from the chocolate packaging and websites. Milk_USA is one of the leading US brands (Hershey Food Corporation), but from the information available, it is difficult to determine the total cocoa content; however, the inference from some published data [17] is that it is in

Table 3 Composition of chocolate test samples

\begin{tabular}{|c|c|c|c|c|c|c|}
\hline Composition & $\begin{array}{l}\text { Cocoa solid } \\
(100 \mathrm{~g})\end{array}$ & $\begin{array}{l}\text { Total fat (satu- } \\
\text { rates) }(100 \mathrm{~g})\end{array}$ & $\begin{array}{l}\text { Milk solids } \\
(100 \mathrm{~g})\end{array}$ & Sugar (100 g) & Emulsifer & Vegetable fat (up to $5 \%$ ) \\
\hline \multicolumn{7}{|l|}{ Family } \\
\hline Dark_A & 36 & $29(18)$ & $\sim 14 \%$ & 57.5 & Soya lecithin & Palm, shea \\
\hline Milk_A & 26 & $30.5(18.5)$ & & 56 & E442, E476 & Palm, shea \\
\hline White_A & $\sim 20$ & $29.5(18.5)$ & & 63 & Soya lecithin & \\
\hline MilkA_USA & $36-42$ & - & - & 56 & Soya lecithin, PG & \\
\hline Candy_EU & $\sim 5$ & & - & & - & Hydrogenated vegetable fat \\
\hline \multicolumn{7}{|l|}{ Luxury } \\
\hline $85 \% \mathrm{~B}$ & 85 & $53.5(32)$ & - & 13.5 & & - \\
\hline $70 \% \mathrm{~B}$ & 70 & $42(25)$ & - & 28.5 & Soya lecithin & - \\
\hline MilkB & 37 & $36(21.5)$ & 24 & 45.5 & Soya lecithin & - \\
\hline WhiteB & 30 & $38.5(23)$ & 26 & 51 & Soya lecithin & - \\
\hline
\end{tabular}


the range $36-42$ wt\% (fat: $29-37 \%$, non-fat cocoa solids: $5-7 \%)$.

\subsection{Examination of Rubbed Chocolate Films}

At the end of the test, the rubbed surface on the microscope slide was examined to determine the composition and morphology of the remaining chocolate film. Examples of the rubbed chocolate sample are shown in Fig. 1b. In the central rubbed region, the film is much thinner as the chocolate has broken down and some components expelled. A differential interference contrast (DIC) microscope was used to examine the component distribution of the rubbed films and compared to images of chocolate prior to rubbing, sampled as thin, melted films. DIC microscopy provides improved differentiation of low-contrast components compared to normal brightfield techniques.

In some tests, rubbed films were prepared on goldcoated microscope slides which allowed analysis by Micro InfraRed Reflection Absorption Spectroscopy (Micro-IRRAS). This technique has been used to analyse the organic composition of small areas of rubbed films on metal surfaces [18]. A Perkin Elmer Frontier FTIR spectrometer equipped with an IR Multiscope microscope was used to take reflection spectra (100 scans, $4 \mathrm{~cm}^{-1}$ ) from small areas $(100 \mu \mathrm{m}$ diameter $)$ of the rubbed chocolate films. All spectra were baseline corrected, smoothed (12 point) and normalised to a common peak absorbance of 0.1 at $\sim 1730 \mathrm{~cm}^{-1}$. More details of the method are given in reference 18 . The rubbed film spectra were compared to fresh (unrubbed) chocolate samples to obtain an indication of component loss during friction testing.

The rubbed films on the gold slides showed very similar features to those formed on glass and the friction curves also showed the same characteristic shapes.

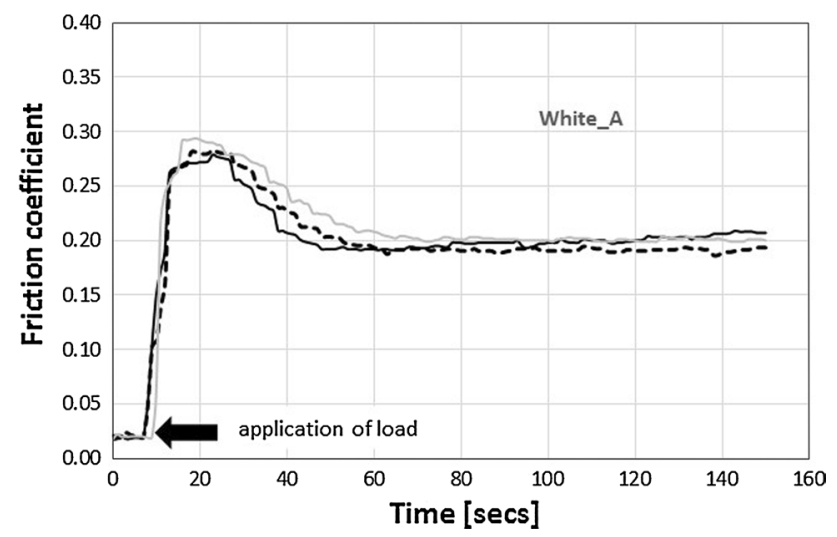

Fig. 2 Friction measurements: test repeats with White_A

\section{Results and Discussion}

\subsection{Friction Results}

Friction results plotted against rubbing time are shown in Figs. 2, 3, 4 and 5. Overall the friction tests were very repeatable, and this is shown in Fig. 2, where three different tests are plotted for White_A. For all other figures, the averaged curves of at least three tests are plotted. Most of the sample showed the same general form of the friction-time curve: an initial increase to a maximum friction coefficient after $\sim 10 \mathrm{~s}$ of rubbing under load, followed by a decrease to a final stable friction value. Differences were observed in the maximum friction attained and the final equilibrium value. In all cases, this value was reached in less than $120 \mathrm{~s}$.

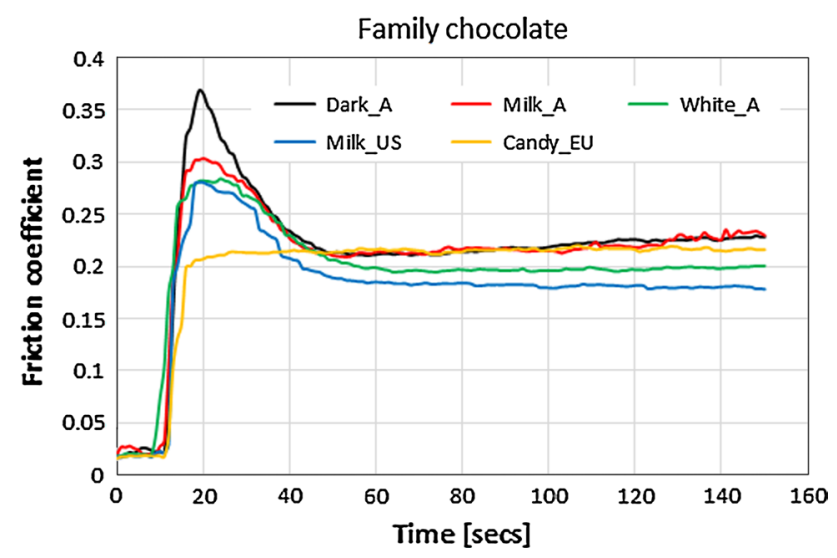

Fig. 3 Averaged friction measurements: comparison of "family" chocolate samples: Dark_A, Milk_A, White_A, Milk_USA, Candy_ $\mathrm{EU}$

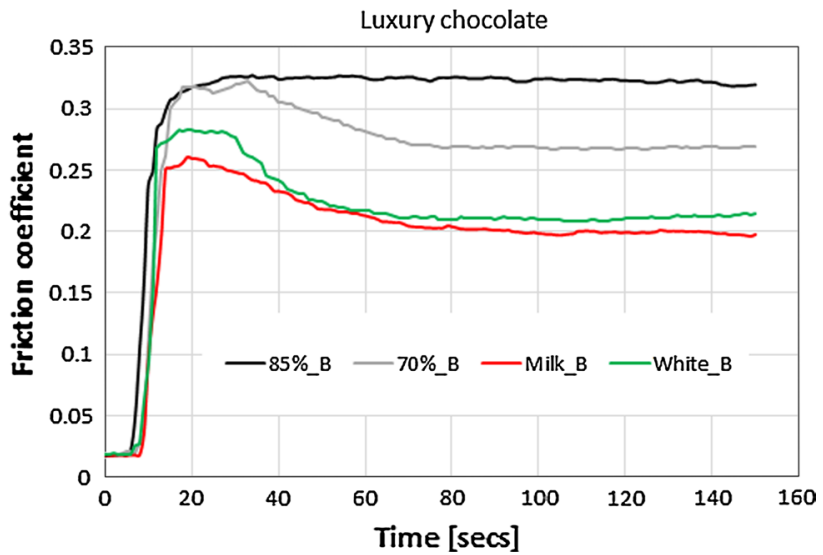

Fig. 4 Averaged friction measurements: "luxury" chocolate; $85 \% \mathrm{~B}$, 70\%B, Milk_B, White_B 


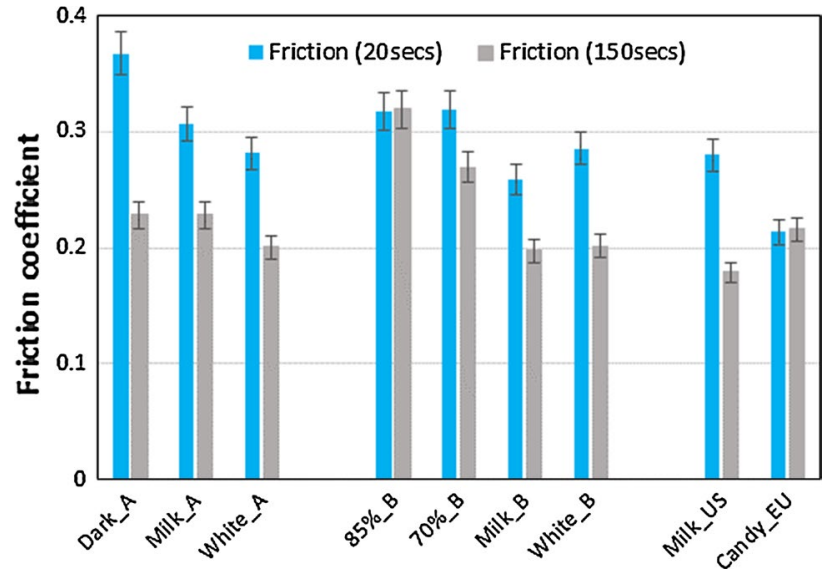

Fig. 5 Summary of friction results: at 20 and 150 s test time (10 and 140 s rubbing, respectively)

\subsubsection{Family Chocolate Friction Results}

Figure 3 compares averaged friction traces for the "family" chocolate samples. The chocolate samples Dark_A, Milk_A and White_A showed very similar friction curve behaviour. Differences were observed in the maximum friction reached after $10 \mathrm{~s}$ of rubbing under load (20 s after start of test), and this ranked with cocoa content (friction coefficient and \% cocoa content is shown in brackets) for products from the same manufacturer (Note Milk_USA and Candy_EU are made by different manufacturers to Dark_A, Milk_A and White_A):

Maximum friction coefficient:

$$
\begin{aligned}
& \text { Dark_A }(\mu=0.37,36 \%)>\text { Milk_A }(\mu=0.30,26 \%) \\
& >\text { White_A }(\mu=0.28, \sim 20 \%) \\
& >\text { Milk_USA }(\mu=0.28,37 \%) \\
& >\text { Candy_EU }(\mu=0.21, \sim 5 \%)
\end{aligned}
$$

Friction coefficient dropped to the minimum value after 40-60 s. Dark_A and Milk_A showed very similar traces with a minimum friction coefficient of $\sim 0.21$, although this increased slightly towards the end of the test $(\sim 0.23)$. White_A gave lower friction values over the test with a minimum value of $\mu=0.195$.

The maximum friction coefficient for Milk_USA was similar to White_A $(\sim \mu=028)$; however, the minimum value was lower $(\mu=0.18)$. The most significant difference was observed for the Candy_EU sample which did not give the initial friction increase but had a fairly constant friction value of $\mu=0.21-0.22$ over the test period. Final friction coefficient results were ranked as follows:
Final friction coefficient:

$$
\begin{gathered}
\text { Dark_A }(\mu=0.23,36 \%) \text { Milk_A }(\mu=0.23,26 \%) \\
>\text { Candy_EU }(\mu=0.22, \sim 5 \%) \\
>\text { White_A }(\mu=0.20, \sim 20 \%) \\
>\text { Milk_USA }(\mu=0.18,37 \%)
\end{gathered}
$$

\subsubsection{Luxury Chocolate Friction Results}

Figure 4 compares averaged friction traces for the luxury chocolate samples. Clear differences are again observed depending on cocoa content. The high content samples (85\%_B and 70\%_B) showed much higher friction coefficients at $20 \mathrm{~s}$. The $85 \%$ B friction trace remained fairly constant over the test time, the 70\%_B friction coefficient decreased after $30 \mathrm{~s}$ rubbing under load ( $40 \mathrm{~s}$ total test time) to a stable value of $\mu=0.27$. The maximum friction coefficient (at $20 \mathrm{~s}$ ) was ranked:

\subsubsection{Maximum Friction Coefficient}

$85 \%$ B $(\mu=0.32,85 \%) \sim 70 \% \_\mathrm{B}(\mu=0.32,70 \%)$

$>$ Milk_B $(\mu=0.28,37 \%)>$ White_B $(\mu=0.26,30 \%)$

The final friction coefficient was ranked:

Final friction coefficient:

$$
\begin{aligned}
& 85 \% \_\mathrm{B}(\mu=0.32,85 \%)>70 \% \_\mathrm{B}(\mu=0.27,70 \%) \\
& >\text { Milk_B }(\mu=0.20,37 \%) \text { White_B }(\mu=0.20,30 \%)
\end{aligned}
$$

Figure 5 summarises initial (at $20 \mathrm{~s}$ test time) and final (150 s test time) friction coefficient results for family and luxury samples. All samples apart from the very high cocoa solid content (85\%_B) and very low cocoa solids content (Candy_EU) show the characteristic drop in friction as the film is rubbed. The origins of this friction change are examined in the next section.

\subsection{Examination of Rubbed Surface Films}

\subsubsection{DIC Microscopy}

Figure 6 shows DIC optical images for melted chocolate samples White_A, Milk_A, 85\%_B and Candy_EU. Similar features are observed for all chocolate types; images are dominated by white sugar crystals (typically $5-30 \mu \mathrm{m}$ diameter) distributed throughout the continuous fat phase. The Candy_EU sample appeared to contain a high percentage of sugar (first named ingredient) with a wide range of crystal sizes and shapes up to $\sim 70 \mu \mathrm{m}$ diameter. In addition, dark fragments of cocoa solids are observed. The apparent diameter of these varied widely across the sample set from 


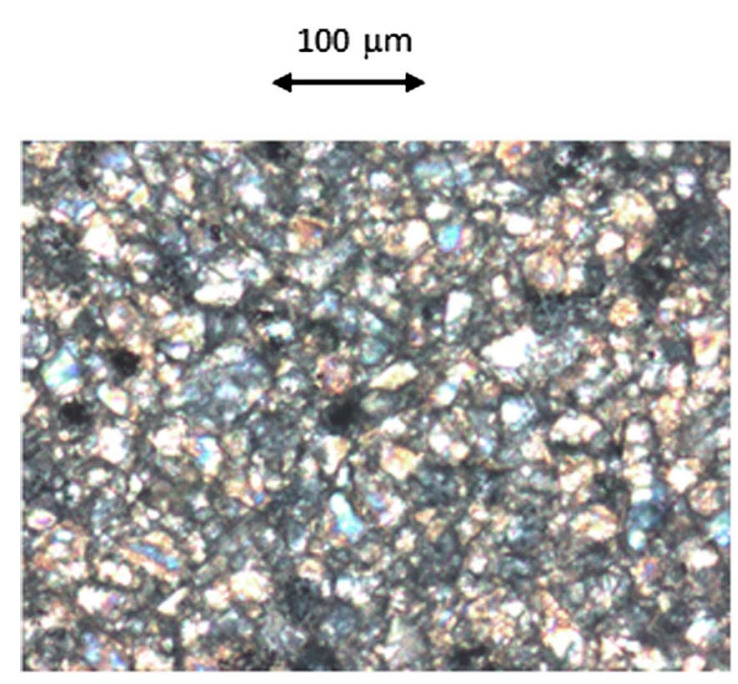

WhiteA

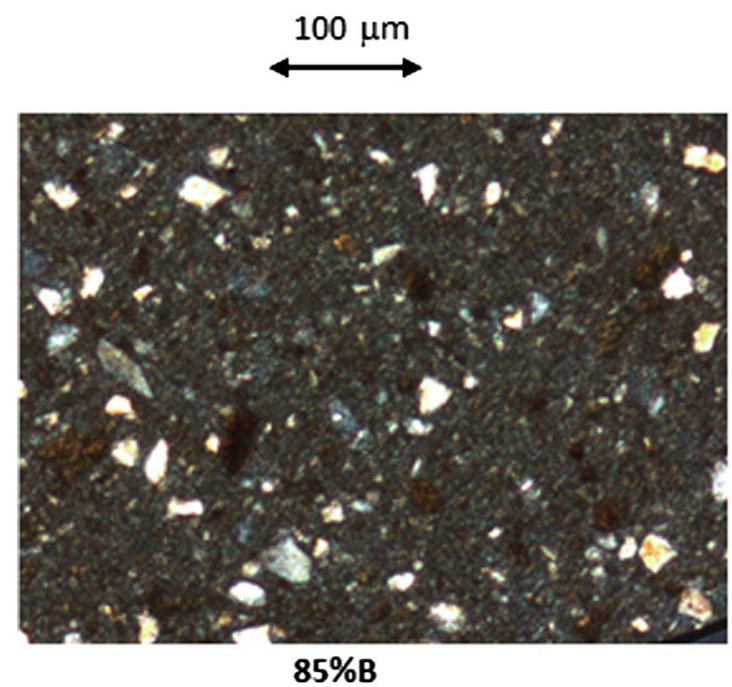

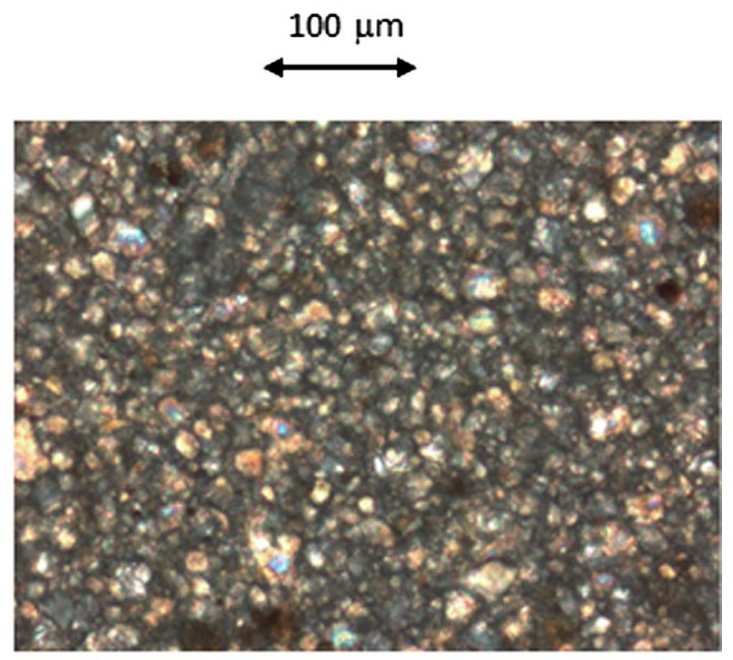

MilkA

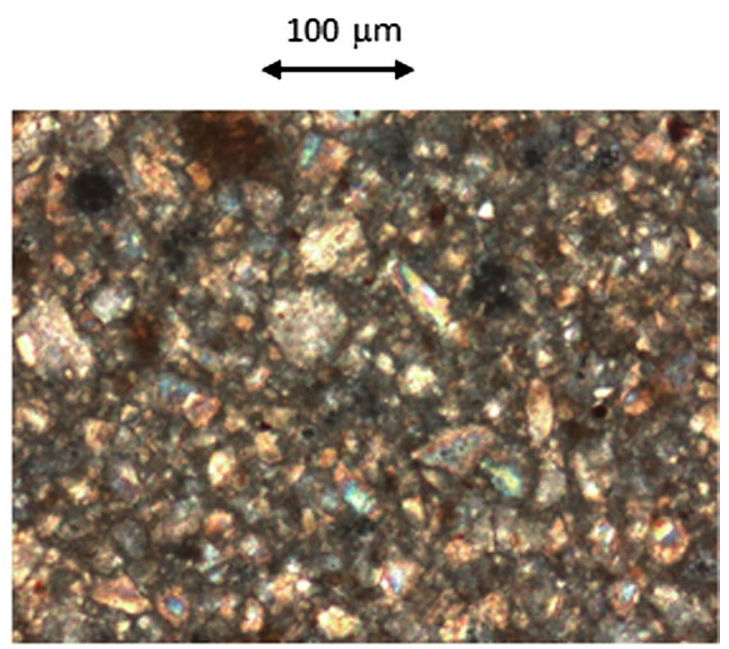

Candy_EU

Fig. 6 Microscope images of melted chocolate films: White_A, Milk_A, 85\%_B and Candy_EU

up $\sim 50 \mu \mathrm{m}$ for Dark_A to less than $10 \mu \mathrm{m}$ for the "luxury" chocolate.

The images from the rubbed films (140 s rubbing) were very different, and examples are shown in Fig. 7. Representative results are shown from tests with Milk_B and White_B: images are shown from the middle and end of the stroke as indicated. Clearly the chocolate structure in the PDMS/glass contact had broken down due to rubbing leaving the lipid phase as a fluid layer. In the confined contact with both surfaces present, these droplets would be expected to form a continuous separating film. In some cases, small particles, possibly mechanically degraded sugar crystals, were also observed associated with the droplets. These appear as a slight "lumpiness" distorting the otherwise smooth lipid droplet and are shown in the higher magnification image in Fig. 7. The only sample which did not breakdown during rubbing was Candy_EU where the sugar crystals appeared to be intact even after 140 s rubbing.

In order to examine the change in the chocolate film, a separate series of experiments was carried out the tests was stopped after 10 and $30 \mathrm{~s}$ rubbing (20 and $40 \mathrm{~s}$ total test time, respectively). Figure 8 shows images taken from a series of tests with Dark_A. Figure 9 shows images for Milk_B after 10,30 and $140 \mathrm{~s}$ rubbing. In both cases there is progressive breakdown of the chocolate structure and release of triglyceride droplets. A slower decay is generally observed in the milk chocolate friction curves, and this appears to be associated with slower structure breakdown. At present, we would not wish to speculate further until more work with chocolate of known composition is carried out. 

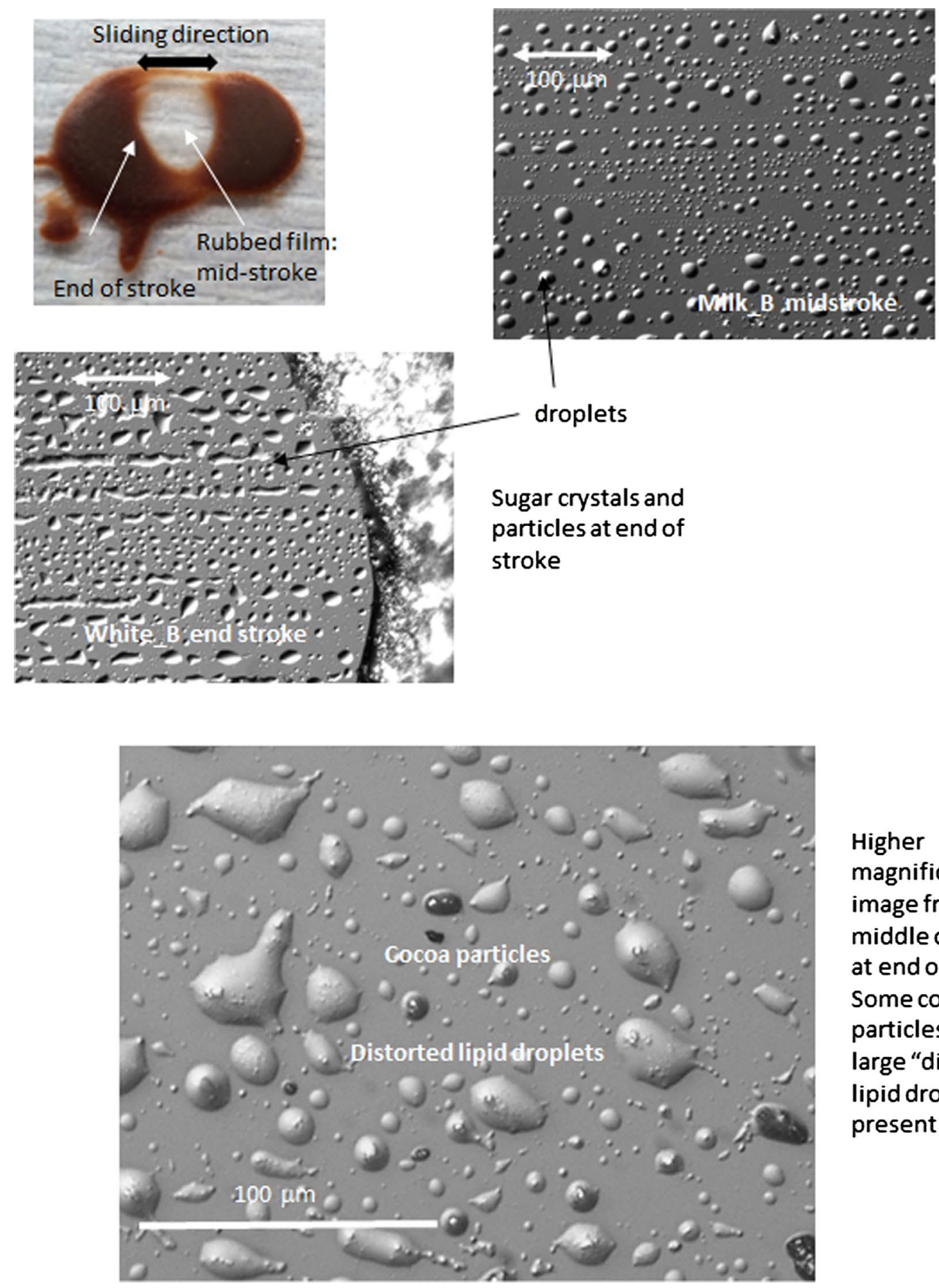

Higher
magnification
image from
middle of stroke
at end of test.
Some cocoa
particles and
large "distorted"
lipid drops are
present

present

Fig. 7 Microscope images of rubbed chocolate films immediately after the test

From the images, we suggest there is a breakdown of the chocolate structure followed by loss of sugar ejected from the contact. In the mouth, sugar is also removed by the action of saliva [8]. Cocoa particles and free lipids released during rubbing preferentially remain in the contact zone. These observations are supported by the MicroIRRAS analysis reported in the next section. 
Fig. 8 Microscope images of rubbed chocolate films at different stages of the test: Dark_A. 1 new melt, 2 mid stroke $10 \mathrm{~s}$ rubbing, 3 midstroke $30 \mathrm{~s}$ rubbing, 4 midstroke $140 \mathrm{~s}$ rubbing
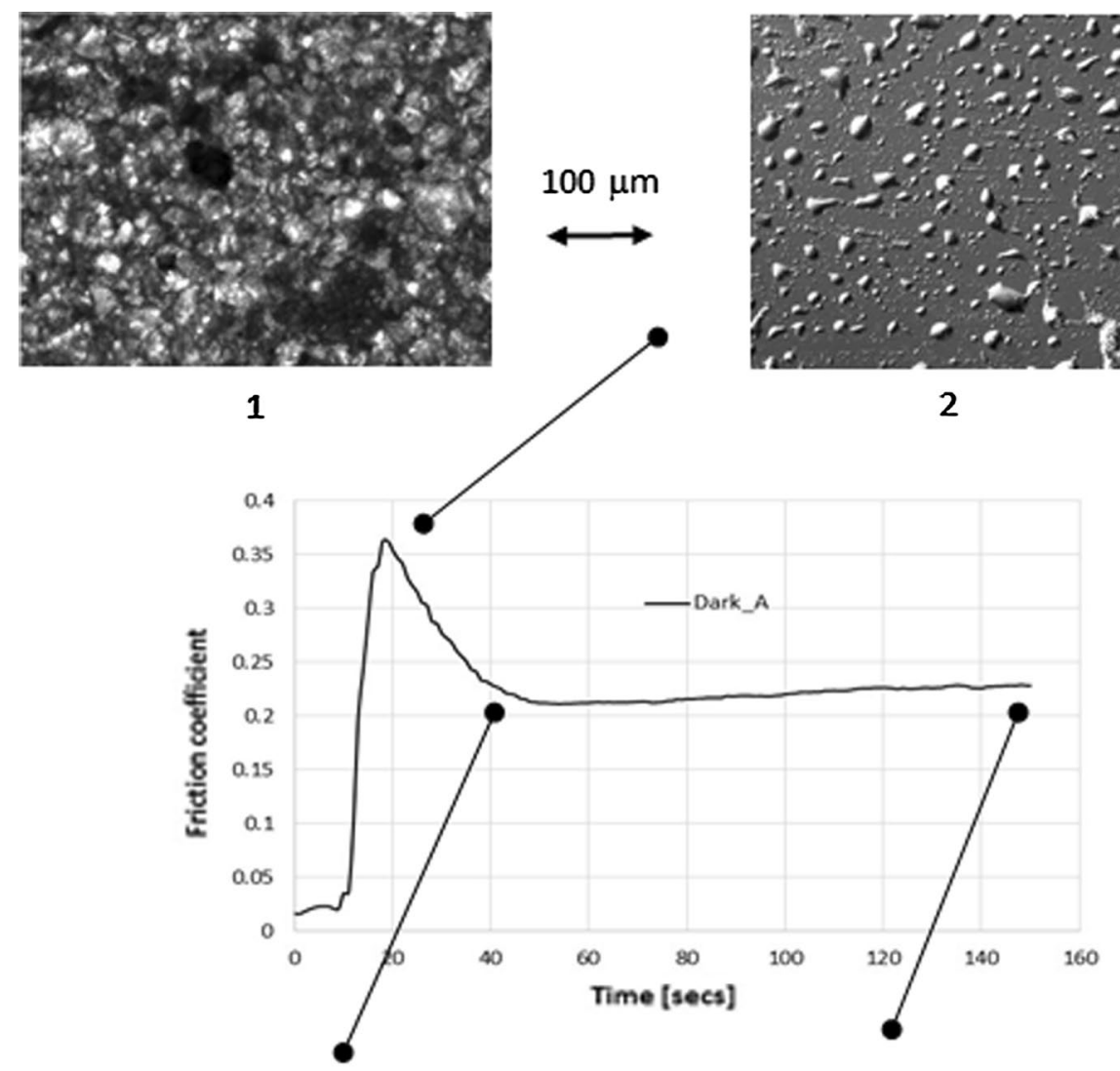

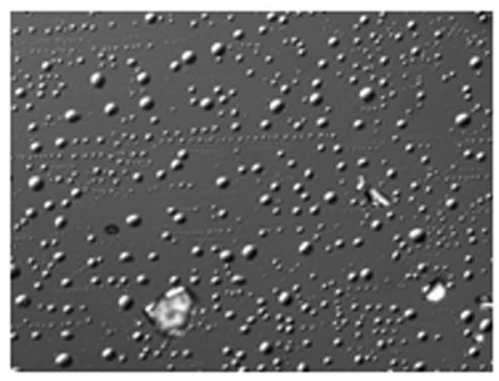

3

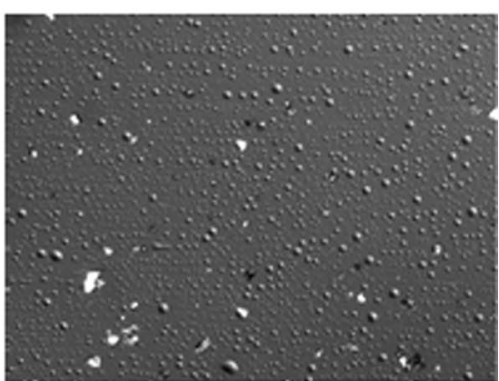

4

\subsubsection{Micro-IRRAS Analysis of Melt and Rubbed Chocolate Films}

Micro-IRRAS spectra of melted chocolate films over the complete spectral range are shown in Fig. 10: for Dark_A, Dark_B, and MilkA_USA. The spectra are complex and show peaks associated with cocoa fat (lipids) and sugar [19]. Figure 11 shows micro-IRRAS spectra of melted chocolate (85\%_B) and cocoa butter films. In this case, limited spectral regions of $3700-2700 \mathrm{~cm}^{-1}$ and $1800-800 \mathrm{~cm}^{-1}$ are shown to improve clarity. The lack of sugar in the cocoa butter samples is seen by the loss of the broad bands in the $3100-3700 \mathrm{~cm}^{-1}$ region which are assigned to various $\mathrm{OH}$ vibrations. A similar reduction is seen in the $\mathrm{C}-\mathrm{O}$ peak intensity in the $1500-1000 \mathrm{~cm}^{-1}$ region [19]. The lipids are primarily seen as an intense, sometimes broad peaks in the $1700-1800 \mathrm{~cm}^{-1}$ region due to the $\mathrm{C}=\mathrm{O}$ bond vibration.

Figure 12 compares micro-IRRAS spectra of rubbed (middle of stroke) and melted chocolate films: 85\%_B for limited spectral regions of $3700-2700 \mathrm{~cm}^{-1}$ and $1800-800 \mathrm{~cm}^{-1}$. The spectrum of melted cocoa butter has been added to the $1800-800 \mathrm{~cm}^{-1}$ graph. Relative loss of sugar bands has occurred, and the remaining peaks are lipids (clearly seen in the lower spectrum), which supports the interpretation of the DIC images. One interesting aspect of the spectra is the change in $\mathrm{C}=\mathrm{O}$ lipid peak position. This is seen clearly in Fig. 13 which compares melt and rubbed spectra for 85\%_B and Milk_A for the limited spectral range of $1800-1700 \mathrm{~cm}^{-1}$. In the melt spectra, the Milk_A C $=\mathrm{O}$ band occurs primarily at $1746 \mathrm{~cm}^{-1}$ with poorly resolved shoulders at $\sim 1755$ and $1735 \mathrm{~cm}^{-1}$. In the 
Fig. 9 Microscope images of rubbed chocolate films at different stages of the test: Milk_B. 1 new melt, 2 mid stroke $10 \mathrm{~s}$ rubbing, 3 midstroke $30 \mathrm{~s}$ rubbing, 4 midstroke 140 s rubbing
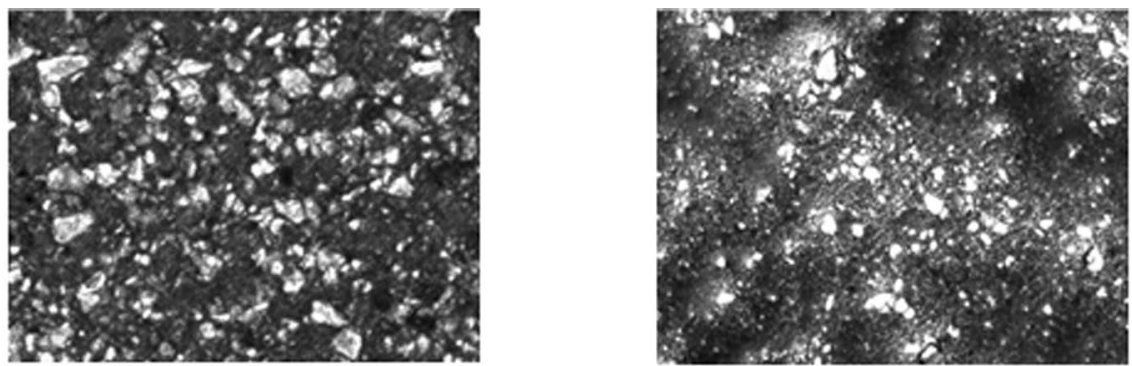

1

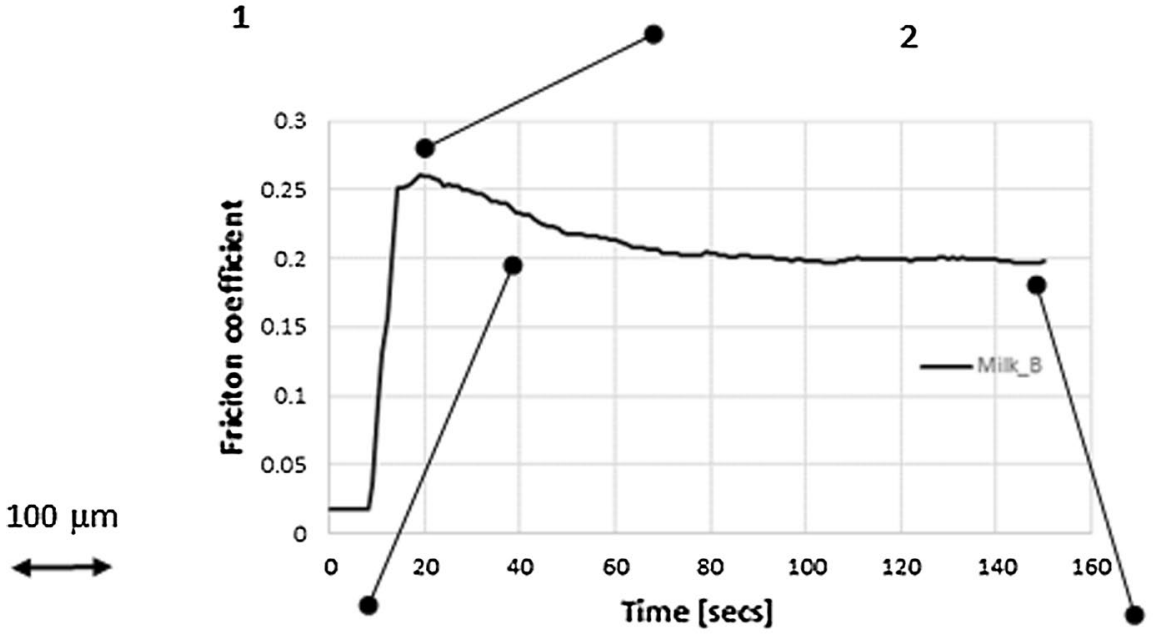

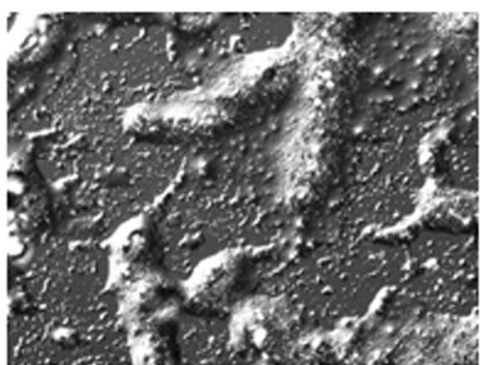

3

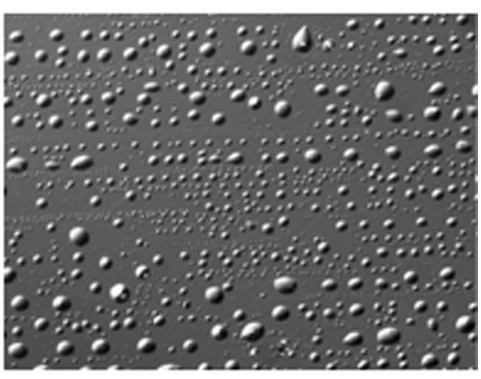

4

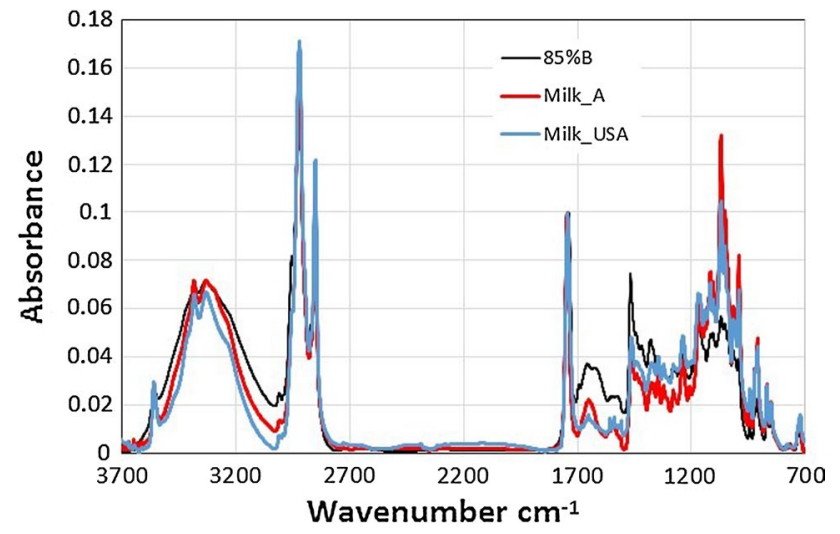

Fig. 10 Micro-IRRAS spectra of melted chocolate films: 85\%_B, Milk_A and Milk_USA rubbed spectra, the dominant $\mathrm{C}=\mathrm{O}$ band is at $1735 \mathrm{~cm}^{-1}$ with a minor unresolved band at $1750 \mathrm{~cm}^{-1}$. In all cases, differences in the position or shape of the lipid $\mathrm{C}=\mathrm{O}$ band were observed for the film deposited at the end of the test. These results suggest changes in lipid composition occurred during rubbing and that preferential loss of some fractions had occurred. It is likely that the changes in the lipid composition contribute to the different friction behaviour of the samples. If this occurs in the mouth, the changing lipid profile as mastication continues might influence the perceived smoothness/creaminess and aftertaste. However, as these were commercial samples where the original lipid mixture was not known, it is unwise to interpret these results further. In addition, the surface properties of the substrate would also determine preferential retention of lipid chemistries. However, PDMS is not a valid chemistry mimic for oral surfaces, and this needs to be improved before the correlation is taken further. 

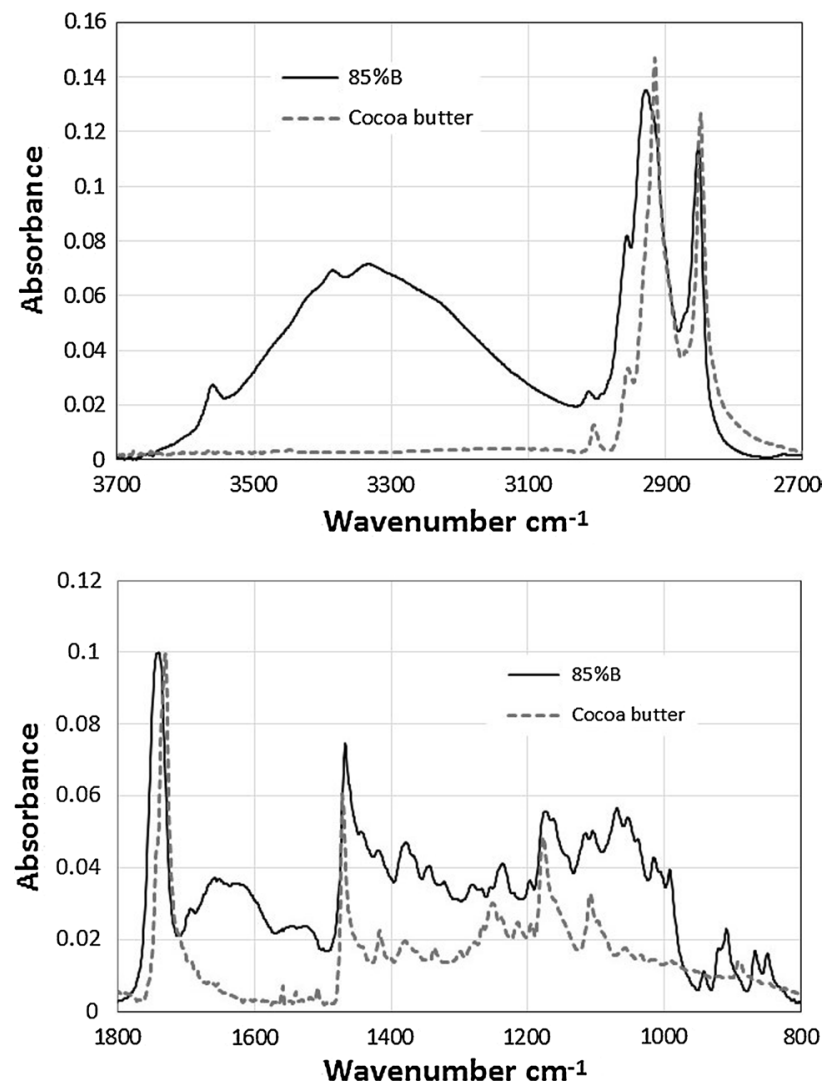

Fig. 11 Micro-IRRAS spectra of melted chocolate (85\%_B) and cocoa butter films. Limited spectral regions of $3700-2700 \mathrm{~cm}^{-1}$ (upper) and $1800-800 \mathrm{~cm}^{-1}$ (lower)

\section{Discussion}

A simple tribology test has been developed to measure friction of molten chocolate as it is mechanically degraded in a rubbing contact. The friction results have shown very different behaviour with rubbing time for the various chocolate types. These results are summarised in Fig. 5. Most of the chocolate samples showed the same type of friction trace: initially high friction dropping to a low and stable value within a few seconds of rubbing. The DIC images of sheared films show degradation of the structure, loss of sugar crystals and formation of a fat-rich film, the nature of which presumably determines the final friction coefficient. The maximum friction coefficient reached in the first $10 \mathrm{~s}$ of rubbing ranks with the total cocoa content within each product group A or B. Group A results and Milk_US showed this behaviour; however, the Candy_EU was very different with a constant friction coefficient over the rubbing period. This product is not classified as chocolate due to the low cocoa fat content and did not appear to mechanically degrade during these tests. The friction measurements were fairly constant over the rubbing time. Similar friction behaviour was observed for the $85 \%$ B sample although in this case
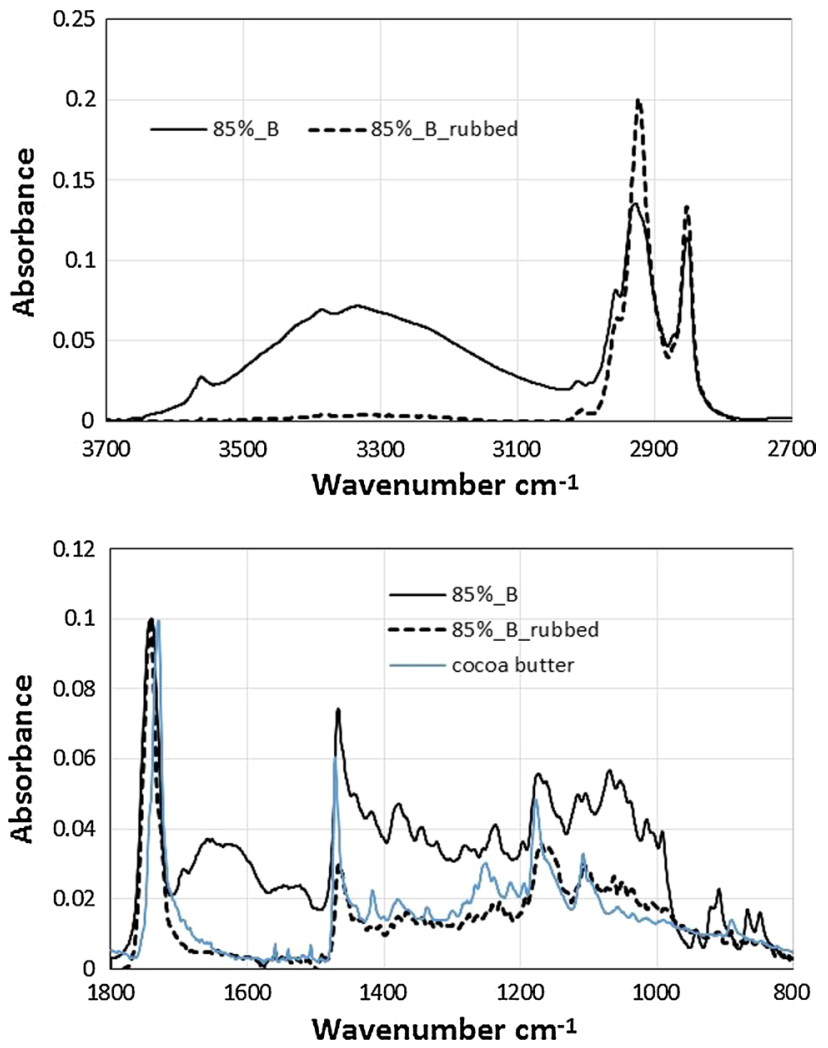

Fig. 12 Micro-IRRAS spectra of melted chocolate (85\%_B) comparison of melted and rubbed films. $85 \%$ B. Limited spectral regions of $3700-2700 \mathrm{~cm}^{-1}$ (upper) and $1800-800 \mathrm{~cm}^{-1}$ (lower). Cocoa butter (melt) spectrum added to lower graph

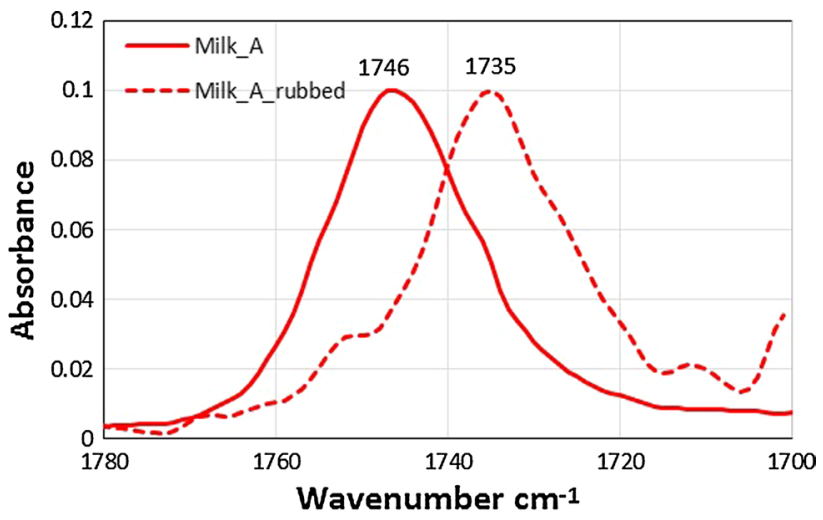

Fig. 13 Micro-IRRAS spectra of rubbed and melt chocolate films. Limited spectral regions of $1780-1700 \mathrm{~cm}^{-1}$ : Milk_A

mechanical degradation had clearly occurred. The reason for this is unclear as the post-test images clearly show loss of structure and the release of fat droplets. From the limited amount of information available, this chocolate did not contain a soya lecithin emulsifier. In an earlier paper, Lee 
et al. $[7,9]$ reported reduction in friction in the slow-speed boundary regime with increasing lecithin content.

The initial friction increase and then decrease with breakdown of the food structure appears to be characteristic of chocolate with a cocoa content in the range 30-70\%. In this way it is possible to differentiate between chocolate and softer cocoa-containing filling found for example in chocolate "truffles". This is shown in Fig. 14 which shows two different friction responses for the casing and inside of a dark chocolate truffle (Marks and Spencer).

The characteristic friction response of chocolate presumably reflects the initial rheology properties of the melt (the initial maximum) followed by mechanical degradation of the structure. This is accompanied by loss of sugar and possibly cocoa particles from the contact zone as the film thins. We suggest the initial friction maximum is where rheology, possibly the yield stress, meets tribology. Afoakwa et al. [10] report initial melting and dissolution of sugar (into saliva) and that at the end of the process the epithelial surfaces are coated with lipids and cocoa solids. Melt chocolate rheology is determined by a number of factors including particle size distribution (typical range 15-30 $\mu \mathrm{m}$ ), composition and manufacture [10]. Although it would be valuable to relate the measured friction curves to rheology and formulation of the chocolate samples at present, this is outside the scope of the paper as these were commercial samples.

The test method allows for the analysis of chemical and morphology changes in the chocolate film during rubbing, and this analysis can be developed further to provide more detailed information on breakdown with time and the changing effects of composition and film thickness. We believe this new approach will provide significant insights into food degradation and mouthfeel during mastication. In the mouth, the composition and film thickness are determined by degradation not entrainment speed. The IR spectra clearly show a reduction in sugar content and preferentially loss of some lipid components. The different lipid profile observed in the

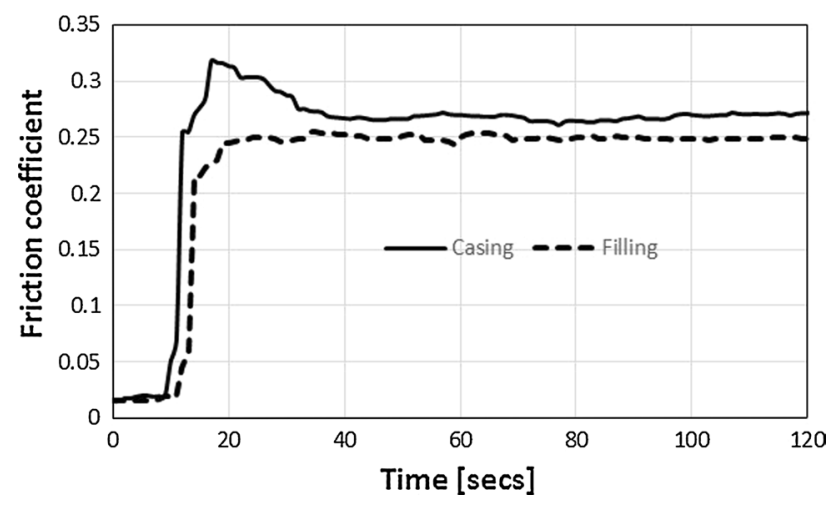

Fig. 14 Averaged friction measurements: chocolate casing and filling of dark chocolate truffle remaining film at end of the test might influence the final friction coefficient (and hence mouthfeel) experienced during mastication. For these samples, we do not have information on the raw materials, and thus it is difficult to interpret this data further.

Existing methods of friction measurement with semifluid food have usually measured friction as a function of entrainment speed [7-9]. The MTM test requires a continued supply of fresh fluid but due to inlet effects the material entering the contact (and thus contributing to measured friction) might have a different composition to the bulk [20]. Our approach attempts to capture the changes that occur during mechanical degradation (mastication) of food and believe this simulates more closely, from a tribology perspective, the eating experience. To achieve full simulation of oral conditions in a tribology test requires the presence of saliva and improved tongue/palate mimics. However, the aim of the current paper was to move away from the "continuous flow" tribology tests as represented by the MTM test [7-9] where the measured friction is dominated by inlet effects to a mechanical degradation test using single, representative food sample. It is possible that the friction profile from initial engagement to final swallow determines the overall mouthfeel. The test is very rapid, provides a better simulation of the oral tribology condition (thin film sheared between softer/hard surfaces) and only uses a very small amount of food $(<0.1 \mathrm{~g})$. It does discriminate between different chocolate types and thus could potentially be used as a screening tool for new chocolate formulations. However, it is acknowledged that the current test design does not capture all oral factors, particularly the effect of saliva on friction, and this will be developed in future work. In addition, two key questions need to be addressed to assess the applicability and usefulness of the test method:

(1) Does the measured friction behaviour correspond to customer experience of mouthfeel and thus perceived creaminess and smoothness?

(2) Do the changes observed in the rubbed chocolate film and the residual lipid surface layer correspond to actual film loss and deposition mechanisms occurring in the oral environment in the presence of saliva?

\section{Conclusions}

The paper reports the development of a novel test method which allows the measurement of friction change with time during rubbing of molten chocolate film in a rubbing contact. The test has been used to distinguish between different commercial chocolate formulations. Our conclusions are as follows: 
(a) Most chocolate formulations have a characteristic friction profile from the start of rubbing: an initial rapid increase and then decay to a final low friction coefficient. The exceptions were the very high (85\%) and very low $(\sim 5 \%)$ cocoa solids content samples.

(b) Friction change is thought to be related to changes in film thickness and the composition of the interfacial layer.

(c) Mechanical degradation of the film in the rubbing contact results in loss of sugar components and release of the lipids to form a continuous phase. It appears the sugar crystals are broken down and expelled from the rubbing zone at either end of the stroke.

(d) Micro-IRRAS analysis indicates changes in the composition of the rubbed film, including loss of sugar and changes in the lipid profile remaining in the contact zone.

(e) Further development of the test is needed to simulate the oral process. This includes the use of saliva (artificial or biological) and improved tissue mimics. Once this has been achieved, the tests might prove useful for the development of new food formulations with optimised oral friction attributes.

Open Access This article is distributed under the terms of the Creative Commons Attribution 4.0 International License (http://creativeco mmons.org/licenses/by/4.0/), which permits unrestricted use, distribution, and reproduction in any medium, provided you give appropriate credit to the original author(s) and the source, provide a link to the Creative Commons license, and indicate if changes were made.

\section{References}

1. de Wijk, A.R., Prinz, R.F.: The role of friction in perceived oral texture. Food Qual. Prefer. 16, 121-129 (2005)

2. Hoskin, J.C.: Sensory properties of chocolate and their development. J. Am Clin. Nutr. 60(Supplement), 1068(s)-1070(s) (1994)

3. Directive 2000/36/EC "Relating to cocoa and chocolate products for human consumption" June (2000)

4. Chevally, J.: An adaptation of the Casson Equation for the rheology of chocolate. J. Texture Stud. 22, 219-229 (1991)
5. Gabriele, D., Migliori, M., Baldino, N., de Cindio, B.: Influence of fat content on chocolate rheology. AIP Conf. Proc. 1027, 12651267 (2008)

6. Afoakwa, E.O., Peterson, A., Fowler, M., Vieira, J.: Comparison of rheological models for determining dark chocolate viscosity. Int. J. Food Sci. Tech. 44, 162-167 (2009)

7. Lee, S., Heuberger, M., Rousset, P., Spencer, N.D.: Chocolate at a sliding interface. J. Food Sci. 67, 2713-2717 (2002)

8. Rodrigues, S.A., Selway, N., Morgenstern, M.P., Motoi, L., Stokes, J.R., James, B.J.: Lubrication of chocolate during oral processing. Food Funct. 8, 533-544 (2017)

9. Lee, S., Heuberger, M., Rousset, P., Spencer, N.D.: A tribological model for chocolate in the mouth: general implications for slurry-lubricated hard/soft sliding counterfaces. Tribol. Lett. 16, 239-249 (2004)

10. Afoakwa, E.O., Paterson, A., Fowler, M.: Factors influencing rheological and textural qualities in chocolate-a review. Trends Food Sci. Technol. 18, 290-298 (2007)

11. Beckett, S.: The Science of Chocolate, 2nd edn. RSC Publishing, London (2008)

12. Tsui, S., Tandy, J., Myant, C.M., Masen, M., Cann, P.M.: Friction Measurements with yoghurt in a simulated tongue-palate contact. Biotribology 8, 1-11 (2016)

13. Mills, T., Norton, I.T., Bakalis, S.: Development of tribology equipment to study dynamic processes. J. Food Eng. 114, 384-390 (2013)

14. Malone, M.E., Appelqvist, I.A.M., Norton, I.T.: Oral behaviour of food hydrocolloids and emulsions. Part 1. Lubrication and deposition considerations. Food Hydrocoll. 17, 763-773 (2003)

15. Hiiemae, K.M., Palmer, J.B.: Tongue movements in feeding and speech. Crit. Rev. Oral Bio. Med. 14, 413-429 (2003)

16. Chojnicka-Paszun, A.: Tribology and sensory attributes of food dispersions. PhD. Thesis. Utrecht University Press (2009)

17. Miller, K.B., Hurst, W.J., Flannigan, N., Ou, B., Lee, C.Y., Smith, N., Stuart, D.A.: Survey of Commercially available chocolate-and cocoa-containing products in the United States. 2. Comparison of Flavan-3-ol Content with nonfat cocoa solids, total polyphenols, and percent cacao. J. Agric. Food Chem. 57, 9169-9180 (2009)

18. Cann, P.M.: The "leaves on the line" problem — a study of leaf residue film formation and lubricity under laboratory test conditions". Tribol. Lett. 24, 151-158 (2006)

19. CheMan, Y.B., Syahariza, Z.A., Mirghani, M.E.S., Jinap, S., Bakar, J.: Analysis of potential lard adulteration in chocolate and chocolate products using Fourier transform infrared spectroscopy. Food Chem. 90, 815-819 (2005)

20. Myant, C., Underwood, R., Fan, J., Cann, P.M.: Lubrication of metal-on-metal hip joints: the effect of protein content and load on film formation and wear. J. Mech. Behav. Biomed. Mater. 6, 30-40 (2012) 